\title{
OPEN DESIGN: abertura + design = prática projetual para a transformação social
}

\author{
Edison Uriel Rodríguez Cabeza \\ FAAC-UNESP \\ carranguero@gmail.com \\ Mônica Moura \\ FAAC-UNESP \\ monicamoura.design@gmail.com
}

Resumo: O presente trabalho é um olhar do design e algumas de suas mudanças geradas pelas tecnologias e pelas novas formas de atuações coletivas em prol de ideias e ideais que permeiam o acesso, a distribuição e a produção de bens, produtos e serviços para a coletividade e sua possibilidade para gerar transformações sociais por meio da recuperação do homem de sua capacidade projetual. Foi elaborada uma indagação sobre o conceito de abertura (Openness) em diferentes campos do conhecimento visando maior e melhor entendimento da abertura e sua implicação no open design, além de uma simples metodologia associada ao movimento do software livre/aberto. Ao final é relatado um caso prático de open design desenvolvido e aplicado na Unesp Bauru. O trabalho está dividido em três partes. A primeira é a construção do conceito de abertura desde diferentes campos do conhecimento; a segunda sobre o conceito de bits e átomos, conhecimento e novas tecnologias; a terceira fala sobre o open design como prática de transformação social junto com uma análise do open design, sua prática no contexto brasileiro e um exemplo ocorrido na Unesp Bauru com o grupo Sagui Lab. Esta artigo visa contribuir para um melhor e mais abrangente entendimento do open design. Pretende, ainda, colaborar para a disseminação e o entendimento do desenvolvimento de produtos, sistemas e serviços materiais e imateriais gerados pelo trabalho livre e colaborativo.

Palavras-chave: Design Contemporâneo, Open Design, Sagui Lab, Inovação Social

\section{OPEN DESIGN: openness + design = projectual practice for social transformation}

Abstract: The present work is a design look and some of its changes caused by technology and new forms of collective actions in support of ideas and ideals that permeate the access, distribution and production of goods, 
products and services for the community and its possibility to generate social changes through recovery of man from his projectual ability. An inquiry was elaborated about the concept of openness in different fields of knowledge aimed at better understanding of openness and its implication on open design, beyond that a simple methodology associated with the movement of the free/open source software. In the end, a practical case of open design happened at UNESP Bauru was related. This work was divided into three parts. The first part is about the construction of the concept of openness from different fields of knowledge. The second part is about of the concept of bits and atoms, knowledge and new technologies. The third part, discusses the open design as a practice of social transformation along with an analysis of open design and its practice in the Brazilian context and an example happened at UNESP Bauru with Sagui Lab group. This article aims to contribute to a better and more comprehensive understanding of open design. It also intends to contribute to the dissemination and understanding of product development, material and immaterial systems and services generated by the free and collaborative work.

Keywords: Contemporary Design, Open Design, Sagui Lab, Social innovation.

\section{INTRODUÇÃO}

O presente trabalho é um olhar do design sobre e algumas de suas mudanças geradas pelas tecnologias e pelas novas formas de atuações coletivas em prol de ideias e ideais que permeiam o acesso, a distribuição e a produção de bens, produtos e serviços para a coletividade. Nesse sentido, e mais especificamente, dirigimos um olhar e a pesquisa ao design aberto, denominado e mais difundido como Open Design. Ou seja, o design por meio de sua capacidade conceitual, projetiva e transformadora que passa a ser permeado por uma nova concepção do fazer advinda da consequência da revolução das tecnologias da informação e do conhecimento, da experiência da cultura do software de código livre/aberto e de sua difusão em outros campos da atividade humana.

Ainda que as tecnologias da informação e do conhecimento sejam a origem da abertura do ponto de vista do desenvolvimento tecnológico, que demarcou, de fato, um antes e um depois da Internet e levou à sociedade mundial ao que hoje se conhece como a sociedade da informação e do conhecimento, suas raízes provêm desde o surgimento da cultura ocidental na Grécia antiga, da conformação das democracias modernas passando pela crise de seus mitos que demarcaram novos olhares sobre o mundo. Foi na crise da democracia entre as duas guerras mundiais que o conceito da abertura passou a ser abordado no campo da filosofia e da política, e depois na década de 60 nas artes. Depois disso, o conceito se expandiu para vários campos do conhecimento, em razão do surgimento das tecnologias da informação e o conhecimento e da fabricação digital, da cultura da Internet e da cultura do software de código livre/aberto, que geraram novos ambientes de criação, de projeto e produção e novas relações entre o usuário, o designer e o produtor, levando à transformação.

A metodologia adotada é de abordagem qualitativa com aplicação de revisão de literatura, pesquisa documental e de campo, estudo de caso e pesquisa experimental. 
O objetivo principal deste artigo é explorar e descrever o open design especialmente no contexto brasileiro. Sendo seus objetivos específicos indagar sobre o conceito de abertura (Openness) em diferentes campos do conhecimento visando maior e melhor entendimento da abertura; descrever a mixagem dos bits e os átomos para depois adentrar no design como disciplina projetual que unida à abertura oferece possibilidades de transformação social. Finalmente, fazer uma descrição do movimento Open Design no contexto brasileiro e seu ecossistema e descrever uma prática de open design na Unesp Bauru com o o grupo Sagui Lab.

Esta pesquisa visa contribuir para um melhor e mais abrangente entendimento Open Design. Pretende, ainda, colaborar para a disseminação e o entendimento do desenvolvimento de produtos, sistemas e serviços materiais e imateriais gerados pelo trabalho livre e colaborativo. E também contribuir para o campo do design indicando as novas formas de organização geradas pela cocriação e pela criação de novos ambientes, cenários e atores envolvidos neste processo que apontam a transdisciplinaridade promovendo ações mais democráticas para a coletividade visando um mundo melhor, mais justo e igualitário.

\section{OPEN MAIS QUE UMA PRÁTICA DE SUCESSO}

O design aberto assume o acesso aberto, o compartilhar, a mudança, a aprendizagem, o conhecimento e habilidades em constante crescimento e evolução. É uma plataforma aberta e flexível em vez de uma fechada. (Hummels, 2011, p. 164). Alguns autores conectam a origem do open design ou design aberto, como consequência do movimento de software aberto e software livre e à conexão e florescimento dos computadores e a Internet (Mul, 2011, p. 36),"como a união do Design (entendido enquanto desenho ou projeto) + open source (código aberto)" (Rossi e Neves, 2011, p. 62). Em certa medida isto é certo uma vez que a primeira definição de open design ${ }^{1}$, segundo Abel et al (2011, p. 12), apareceu com a fundação da organização sem fins lucrativos denominada ODF (Open Design Foundation Fundação de Design Aberto) que tentou descrever esse novo fenômeno. Essa definição, segundo a ODF (2000), derivou da definição de código aberto escrita por Bruce Perens como o guia de definição de software livre da Debian Free Software em 1997, que foi a base da definição de Software aberto da OSI ${ }^{2}$ (Open Software Initiative).

Mas conectar o open design só com o movimento de software livre/aberto tem algumas limitantes. A primeira delas surge da discussão entre os partidários do software livre como postura filosófica e ética frente à liberdade dos usuários e os partidários do software aberto como uma prática metodológica para obter resultados específicos, e marketing comercial. Em segundo lugar, sempre teve abertura no desenvolvimento de artefatos na história humana, e em terceiro lugar, o conceito de abertura não pode ser visto simplesmente como uma metodologia, uma prática de sucesso com umas regras que devem ser cumpridas para merecer o selo de garantia de aberto. A abertura é importante porque tem implicações para a evolução da sociedade em termos de liberdade, justiça, igualdade, democracia, inovação, entre outras, que unidas a uma disciplina projetual como o design é convertida em uma ferramenta importante para a transformação e evolução da sociedade como veremos a seguir.

\footnotetext{
${ }^{1}$ http://www.opendesign.org/odd.html

${ }^{2} \mathrm{http}: / /$ opensource.org/osd
} 


\section{A ABERTURA}

A ideia da abertura tem feito parte das narrativas do Ocidente desde antes do florescimento da democracia moderna e da "economia do conhecimento". Segundo Peters (2010, p. 107), essas narrações têm sido principalmente grandes histórias da natureza da liberdade, a primazia dos direitos à livre expressão, a constituição da esfera pública ou o bem comum, e o vínculo íntimo entre abertura e criatividade. Segundo Popper (1974, p. 191) o processo de transição de uma sociedade fechada para uma aberta é uma das revoluções mais profundas da humanidade, que inicia na Grécia antiga e ainda está no inicio.

Popper (1974, p. 188) e Bergson (1935, p. 229), coincidem em descrever as sociedades fechadas como aquelas sociedades mágicas, tribais onde têm predominância a supervivência, a religiosidade, a negação do individuo e a razão, a predominância do grupo, o tabu, os instintos, a predisposição para a batalha. Pelo contrário as sociedades abertas são uma defesa da sociedade que se contrapõe ao totalitarismo, democráticas, igualitárias, onde o individuo e a razão toma preponderância. A sociedade aberta ou democrática é definida por Popper (Popper, 1974 , p. 188) como "aquela sociedade em que os indivíduos são confrontados com decisões pessoais". O individuo faz parte das decisões da sociedade e pode ascender na escala do poder, ao contrario da sociedade fechada onde as decisões são tomadas por o chefe tribal, rei ou sacerdotes inamovíveis. Bergson (1935, p. 230), diz que a sociedade aberta é a sociedade que é considerada, em princípio, para abraçar a toda a humanidade.

Para Peters (2010, p. 107), é a lógica dos sistemas abertos que tem a capacidade de mudar profundamente todos os aspectos de nossos sistemas atuais da ciência, a saber, a política, a cultura e a economia que conduzem ao que outros têm aludido como culturas abertas. Como parte da teoria dos sistemas, Bertalanffy (1956) desenvolve o conceito de sistemas abertos que surgiu das discussões dos biólogos no final do século XIX e princípios do século XX sobre o funcionamento dos organismos vivos e sua relação com o meio. Um sistema aberto é definido por Bertanlanffy (1976, p. 146) como: "um sistema que troca matéria com o ambiente circundante, que exibe importação e exportação, constituição e degradação de seus componentes materiais".

A abertura "Opennes", segundo Mul (2011, p. 37), é um conceito que se fez especialmente popular nas duas últimas décadas, que tem tomado importância nas discussões sobre a contemporaneidade graças à gradual transformação dos enfoques fechados e mecanicistas dos meios científicos, tecnológicos e culturais, para modelos abertos, complexos e transdisciplinares. Dado que o tratamento simplista e mecanicista resultava insuficiente para se enfrentar problemas teóricos, especialmente nas ciências biossociais, e a os problemas práticos propostos pela tecnologia moderna, surge assim o enfoque em sistemas (Bertanlanffy, 1976, p. 10).

Assim desde a lógica de os novos enfoques científicos, Eco (1962) em seu ensaio "Obra Aberta", fala da visão einsteiniana que oferece a ambiguidade e as infinitas possibilidades de interpretações e leituras da obra, do caos em sua relação entre ordem-desordem, em que uma obra em movimento nega uma única experiência, isso não implica o caos das relações, mas a regra que permite a organização das relações, as obras de arte são inacabadas, sem direção estrutural e com muitas possibilidades de organizações; todo o contrario ao que acontece com as obras da Idade Média caracterizadas por seu caráter unívoco, unidirecional, ordenado e dominado por hierarquias claras e predeterminadas pelo logos criador. Ele conclui 
que "a obra em movimento, em suma, é a possibilidade de uma multiplicidade de intervenções pessoais, mas não é um convite amorfo à intervalo indiscriminada". (Eco, 1991, p. 62)

Como exemplos representativos da obra aberta no Brasil, podemos nos remeter às obras de Lygia Clark e Hélio Oiticica, artistas brasileiros que produziram obras que se completavam só com a participação ativa do fruidor ou observador, que nesse caso assume nova posição tornando-se agente e cocriador da obra. Oiticica transforma em sua obra o papel do fruidor para um "participador" aberto a um novo comportamento que o conduz ao exercício experimental da liberdade, possibilitando uma nova atitude ética, de participação, coletividade e mudança.

Com o fruidor como participante a obra, implica para a arte o apagamento do artista como autor da obra, ou em termos da literatura citando as palavras de Barthes (1998, p. 70) "Para devolver à escritura o seu futuro, é preciso inverter o mito: o nascimento do leitor deve pagar-se com a morte do Autor". No contexto do design aberto acontece um fenômeno similar: o papel do designer se transforma radicalmente nos processos de criação e confeç̧ão do produto que entra numa dimensão complexa, a linha divisória entre o designer, o fabricante e o usuário se dilui.

No campo da psicologia a abertura é abordada por Robert R. McCrae (1996), quem faz uma revisão dos efeitos da abertura (openness) versus fechamento (closedness) na inovação cultural, ideologia política, atitudes sociais, escolha marital e as relações interpessoais. Em seu trabalho, McCrae, fala que, dos cinco fatores que definem a personalidade humana, a abertura à experiência é a dimensão da personalidade que mais influencia os fenômenos sociais e interpessoais, que podem influenciar a sociedade para uma mudança cultural, política, padrões de amizade, família e relações de casal, porque "a abertura se manifesta na amplitude, profundidade e permeabilidade da consciência e na necessidade de repetição para ampliar e examinar a experiência". (McCrae, 1996, p. 323)

A abertura é uma visão ampla e geral que tem relação com a fantasia viva, a sensibilidade artística, a profundidade dos sentimentos, a flexibilidade compartimentar, a curiosidade intelectual, as atitudes não convencionais, como a personalidade inventiva, as tênues fronteiras mentais, a intuição, o engajamento intelectual, entre outros. (McCrae, 1996, p. 323)

Influenciada pela teoria dos sistemas abertos e fazendo uma crítica aos processos de inovação fechados, onde a empresa gera, desenvolve, fabrica e comercializa suas próprias ideias, Henry Chesbrough (2003), propõe o conceito de inovação aberta, onde a empresa abre seus limites de inovação, permitindo entrar outros atores em seu processo de inovação, criando uma gama mais ampla de atores envolvidos, que inclui outras empresas, universidades de pesquisa tecnológica públicas e privadas, bem como indivíduos. O limite entre a empresa e seu meio circundante é o que permite às inovações se mover facilmente entre os dois. (Chesbrough, 2011, p. 37)

A abertura está se tornando uma forma organizacional que oferece um novo modelo comercial e cultural, além disso, pode oferecer a possibilidade para a sobrevivência e a superação dos problemas atuais, como realça Thackara (2011, p. 44), os problemas sistêmicos, como a mudança climática, e o esgotamento de recursos não podem ser resolvidos com as mesmas técnicas que os causaram. Pesquisa aberta, design aberto e governo aberto são condições prévias para o contínuo, colaborativo modo de vida social de pesquisa e ação que são necessários. 


\section{BITS E ÁTOMOS}

Com os novos avanços tecnológicos, o conhecimento e a informação se converteram na base da economia, na principal força produtiva neste momento da contemporaneidade. $\mathrm{O}$ conhecimento pode se expandir globalmente, organizar-se e fazer-se mais acessível a qualquer pessoa que possa estar interconectada, além disso, o conhecimento formal pode ser convertido em Bits e ser difundido a um custo baixo e ser materializado de novo. "Todo conhecimento passível de formalização pode ser abstraído de seu suporte material e humano, multiplicado quase sem custos na forma de software e utilizado ilimitadamente em máquinas que seguem um padrão universal". (Gorz, 2005, p. 10)

A construção do conceito de "Bits versus átomos" foi originada como o trabalho de pensadores do MIT Media Lab, por seu fundador Nicholas Negroponte, e atualmente com Neal Gershenfeld no MIT centro de bits e átomos (center for bits and atoms) que se refere a uma distinção entre software e hardware ou tecnologia da informação e qualquer coisa. Gershenfeld $(2005$, p. 4) considera que não existe uma separação entre a ciência da computação e a ciência física, com isso, é possível mediante programas processar tanto os átomos como os bits, digitalizando a fabricação da mesma forma que as comunicações e a computação foram anteriormente digitalizadas, assim, aparelhos de fabricação podem ter a capacidade de fazer tudo por meio da montagem de átomos.

A mesclagem entre os bits e os átomos torna possível que várias expressões da vida social sejam passíveis de digitalização e também que sejam transmitidas instantaneamente a qualquer lugar do mundo interconectado. É assim que a sociedade e os indivíduos têm a possibilidade de acessar, criar, modificar, publicar e distribuir as informações e o conhecimento digitalizado, construindo o conhecimento coletivo e enriquecendo a cultura global e a local. Assim, segundo Anderson (2012, p. 14), os computadores aumentam o potencial humano: eles não dão somente às pessoas o poder de criar, mas também o poder de espalhar as ideias, criando comunidades, mercados e movimentos.

Nesse contexto, as tecnologias da informação e o conhecimento, a cultura hacker e o modo de produção Commons-based peer production são os fundamentos que deram um novo enfoque à abertura da sociedade e origem ao movimento do software livre e do software de código aberto, cujas práticas foram espalhadas por muitos campos do conhecimento, não só os digitais, mas também os físicos e analógicos que estão permitindo as transformações tecnológicas que prometem inverter a estrutura atual das ferramentas e criar novas formas de produção abertas aos usuários designers, fabricantes e comunidades, como alternativa ao modelo de desenvolvimento fechado e lineal atualmente em crise. A ideia da fábrica da Revolução Industrial está mudando, segundo Anderson (2012, p. 14), assim como a Web democratizou os bits, uma nova classe de tecnologias de "prototipagem rápida", como impressoras 3D e cortadores a laser, está democratizando a inovação nos átomos.

$\mathrm{O}$ conceito de Commons geralmente se refere a "um recurso compartilhado por um grupo de pessoas" (Hess e Ostrom, 2007, p. 4) ou de uma forma institucional específica de estruturar os direitos de acesso, uso e controle de recursos (Benkler, 2006, p. 60). Segundo Benkler (2006, p. 61), a característica marcante dos commons é a oposição à propriedade, que nenhuma pessoa tenha o controle exclusivo sobre o uso e disposição de qualquer recurso, em especial dos bens comuns -valores consistentes no bem de todos ou da coletividade. Bens de cuja utilização não pode ser excluído 
qualquer membro da coletividade-. Com respeito ao termo "peer production" (produção entre pares), refere-se a uma série de práticas de produção baseada em commons, ou seja, um sistema de produção que depende da ação individual que é autosselecionada e descentralizada e não imposta hierarquicamente. (Benkler, 2006, p. 62)

A cultura hacker é composta por indivíduos que sentem emoção para resolver problemas e acrescentar suas habilidades para exercitar sua inteligência, em eles pode-se observar os efeitos da abertura em uma sinergia econômica, social, cultural, tecnológica e política, que potencializa a inovação e gera mudanças radicais na sociedade, revalorizando a cultura da liberdade, a participação, a colaboração e a oposição à sociedade fechada, não só no âmbito dos bits mas também no átomos.

Podemos indicar a possibilidade de estarmos às portas de um modo de produção livre, baseado nas práticas cooperativas, que, além de compartilhar conhecimento e informação, compartilha artefatos para usar, criar, modificar, aplicar às nossas próprias necessidades em seus próprios contextos socioculturais, garantindo a liberdade em uma nova "mistura", integração ou miscigenação entre usuários, comunidades, fabricantes e designers. Uma nova era de inovação está surgindo, a fabricação digital é a possibilidade de emancipação do indivíduo diante do trabalho, em seu entorno físico, econômico, social, político e cultural. Os dez anos passados do século XXI têm sido sobre a descoberta de novas formas de criar, inventar e trabalhar juntos na Web, os próximos dez anos vão ser sobre como aplicar essas lições no mundo real. (Anderson, 2012, p. 17)

\section{OPEN DESIGN: O FAZER E O PENSAR}

O open design existe desde muito tempo atrás. A natureza humana se baseava na transformação de seu ambiente natural, no design de seu mundo artificial, assim, o conhecimento inerente aos artefatos era compartilhado e melhorado. O intercâmbio de informação e conhecimento na primeira Revolução Industrial foi importante para o desenvolvimento e melhoramento de tecnologias. Bessen e Nuvalori (2011, p. 12) chamam esse fenômeno de "invenção coletiva". Para esses autores, é claro que as tecnologias-chave da industrialização, como as máquinas de vapor de alta pressão, entre outras, eram em momentos e lugares, desenvolvidas por meio de processos de invenção coletiva. Poder-se-ia dizer que são os primórdios do design aberto no contexto moderno.

Cross (2008, p. 11-12) descreve a os seres humanos sempre projetando coisas, adaptadas aos seus próprios propósitos. Projetar coisas é inerente aos seres humanos, por isso, não sempre tinha-se considerado requerer de habilidades especiais, o fazer e o projetar não estavam separados, até que nas sociedades industriais modernas as atividades de design e fabricação de artefatos ficaram muito separadas. Assim, quase todo o controle do mundo objetual ficou nas mãos da indústria que fechou seus processos de inovação e produção, apoiados em segredos industriais, marcas, patentes e direitos autorais, que impôs seus parâmetros aos objetos e eliminou a possibilidade de adaptação ao ambiente natural do ser humano modernizado, ficando este à mercê desses produtos. Com a falta de controle dos artefatos, segundo Aicher (2001, p. 133), o homem perdeu o controle de sua produção de artefatos e a capacidade de alterar o seu ambiente, em troca disso, segundo Illich (1973, p. 17), os humanos foram degradados à condição de meros consumidores. 
Ao considerarmos que o design tem sido utilizado para conservar e expandir os atuais padrões de vida, produção e consumo, e de certa forma, manipulando o consumidor e o mercado a partir de uma significação equivocada que remete este campo apenas à produção da aparência, da forma exterior das coisas e dos objetos, produzindo valores simbólicos, estéticos e sociais apoiados pela mídia em geral, pela publicidade em particular e pelo marketing, sendo esses aspectos amplificados e interrelacionados à sociedade de consumo, pode-se considerar que os princípios basilares do campo do design foram perdidos ao longo do tempo ou estão sendo empregados de forma equivocada. Ante a crise atual, tomam vigência as ideias de Papanek (1977, p. 13), de projetar para o mundo real, de Converter o design num utensílio inovador, altamente criativo, e interdisciplinar que responda às verdadeiras necessidades do homem.

Bonsiepe (2011, p. 21), propõe como rumo do design a práxis de um humanismo projetual, em que sejam utilizadas as capacidades projetuais do designer para interpretar as necessidades de grupos sociais e elaborar propostas viáveis, emancipatórias, em forma de artefatos instrumentais e artefatos semióticos. Esse humanismo projetual implica na redução da dominação e, no caso do design, na atenção aos excluídos, aos discriminados, aos invisíveis que são a maioria deste planeta. Para Aicher (2001, p. 136-137), perante os tempos atuais de crise, já não é possível só conhecer o mundo, para ele chegou a hora de projetar o mundo, por isso o design já não é há muito tempo um conceito somente projetual; aponta agora ao âmbito da filosofia, da explicação do mundo e a compreensão da época sobre como procuramos o acesso a um mundo que já não e só objeto de conhecimento. Devemos passar do pensar ao fazer, e no fazer, aprender de novo a pensar.

Illich (1973, p. 16-17), propõe que essa crise da produção industrial pode ser revertida somente se o homem aprender a inverter a atual estrutura das ferramentas, pois as ferramentas têm que trabalhar para o homem e garantir seu direito ao trabalho com eficiência, aumentar sua independência e liberdade, eliminar a necessidade de escravos e peritos, aproveitar ao máximo a energia e a imaginação que cada um tem. Além disso, Illich também destaca que as pessoas não precisam só obter coisas, precisam, sobretudo da liberdade de fazer coisas, lhes dar forma de acordo com seus gostos, usá-las, cuidá-las entre outras coisas.

Estamos num momento crucial em que a capacidade projetual do design unido às tecnologias da informação e o conhecimento e às ferramentas de fabricação digital, faz que a abertura seja mais que umas simples regras para abrir as fontes de um produto, sistema o serviço para que possa ser "livre" ou "aberto". Agora a apertura desde um conceito mais amplo, implica um novo jeito de fazer, experimentar e produzir os meios tecnológicos, produtos, serviços e sistemas de acordo com regras democráticas e inclusivas permitindo a participação ativa dos indivíduos, comunidades e atores envolvidos em todo o ciclo de vida do produto, oferecendo soluções que incentivem a criatividade, favorecendo a inovação, e, fundamentalmente, evitando o fechamento da sociedade e o retrocesso nos avanços de abertura que a humanidade tem alcançado até o momento, oferecendo caminhos diferentes dos modelos fechados e lineares pelos quais transitar. Design e abertura implica agora projetar serviços livres, produtos livres, sistemas livres e sociedades livres, é uma filosofia projetiva do ambiente humano, que por meio da inovação social ou coletiva, oferece soluções diferentes autogestionadas que nem o Estado nem os modelos lineares oferecem. 


\subsection{Movimento de design livre/aberto no brasil}

O movimento de design Livre/aberto no Brasil está sustentado num ecossistema de indivíduos, usuários, designers, fabricantes, fazedores ou comunidades frequentemente associados para produzir conteúdos culturais, conhecimento, hardware, software e outros tipos de informações, e, no caso do Open Design, produtos, sistemas e serviços que oferecem soluções a seus interesses particulares ou comunitários. A maioria dessas pessoas cria espaços de encontro, discussão, fabricação, aprendizagem, desenvolvimento e design como hackerspaces, fablabs, makerspaces, 1000k garagens, plataformas de discussão e compartilhamento, lojas tecnológicas, transformando, mesclando e criando, suas ideias e as ideias de outros em objetos tangíveis e ferramentas de produção e fabricação digital. A informação e o conhecimento produzido é compartilhado pela internet, por meio das redes sociais, blogs, grupos virtuais, sites e plataformas especializadas desenvolvidas por eles em uma sinergia local-global, para que possa ser copartilhada, modificada, distribuída, visualizadas, misturada, entre outros.

Alguns exemplos desses espaços e plataformas no contexto brasileiro são: os Fab Lab' s: Fab Lab São Paulo, Garagem FabLab; os Hacker Spaces: Garoa Hacker Clube, Área 31, Hacker ônibus; os Maker Spaces: CADEP (Centro avançado de desenvolvimento de produtos da UNESP), Pedro Terra Lab, Corte Recorte, Sites de compartilhamento como: Fazedores, Corais, Materiabrasil, DIY Brasil, Open Hardware Brasil; além disso, existem outros projetos de desenvolvem hardware e ferramentas de fabricação digital como:, Metamáquina, RepRap Brasil, Pandora Open CNC, entre outros, que dá a liberdade de controlar a tecnologia e ao mesmo tempo compartilhar conhecimentos e estimular a comercialização por meio do intercâmbio aberto dos designs. (Free Cultural Works, 2012).

Ao estar baseada a economia do design nos bens comuns, surge um novo modelo econômico: o trabalho voluntário toma preponderância, surge o consumo colaborativo e se criam novas formas de intercâmbio não necessariamente baseadas no dinheiro, como a troca de conhecimentos, produtos, serviços ou tempo como em Bliive ou timerepublik, o mesmo moedas digitais independentes dos bancos centrais como o Bitcoin, litcoin entre outras. Muitas das ideias e projetos desenvolvidos no ambiente open são financiadas pelas mesmas comunidades mediante seus próprios sistemas de financiamento coletivo (crowdfunding) como Catarse, Kickante, Impulso, que são submetidas ao público quem decide quais projetos financiar.

Também existe um ambiente legal para manter os produtos livres e não sejam privatizados por marcas, patentes ou direitos autorais, para isso são criados vários tipos de licenças, como as licenças Creative Commons, GNU-GPL, entre outras.

\subsubsection{Sagui Lab: uma experiência de design aberto e trabalho colaborativo na Unesp}

O projeto Sagui Lab é um projeto desenvolvido pelos alunos do curso de graduação e pós-graduação em design da UNESP que inicia suas atividades em outubro de 2013, que tem como proposta a prática da criação colaborativa, o uso de técnicas de fabricação digital, a multidisciplinaridade, o uso de espaço compartilhado e o desenvolvimento de projetos inovadores em multiplataforma digital. O Sagui Lab é uma iniciativa que pratica e divulga o "Open Design" (metodologia aberta para a produção de objetos e forma em design) e outros métodos colaborativos para o desenvolvimento de projetos dentro do Campus da Unesp Bauru. 
O Sagui Lab tem realizado várias atividades e oficinas de 'gambiarras', fabricação digital de mobiliário, prototipagem eletrônica com Arduino, software livre, cocriação e trabalho colaborativo. Dentro das atividades mais sobressalientes esta experiência de fabricação digital e design Livre/aberto, e desenvolvida por o CADEP (Centro Avançado de Desenvolvimento de Produtos), com o objetivo de realizar uma campanha de promoção das tecnologias de fabricação digital do CADEP, e a fabricação do mobiliário para as instalações do Sagui Lab mediante procedimentos de fabricação digital e projetados de forma colaborativa como se pode observar nas figuras 1 , fonte: Sagui Lab, 2, fonte: o CADEP, 3 e 4, fonte: Sagui Lab. Nessa mesma atividade se realizaram testes de móveis de código aberto baixados de plataformas de compartilhamento como OpenDesk e Sketchair, um software de código aberto que permite a qualquer um projetar, modificar, adaptar e construir facilmente cadeiras digitalmente. Um integrante do Sagui Lab entrou nesses sites, baixou os arquivos digitais e em um MakerSpace, como o CADEP, teve acesso a uma máquina de usinagem CNC para fabricar sua cadeira com um click.

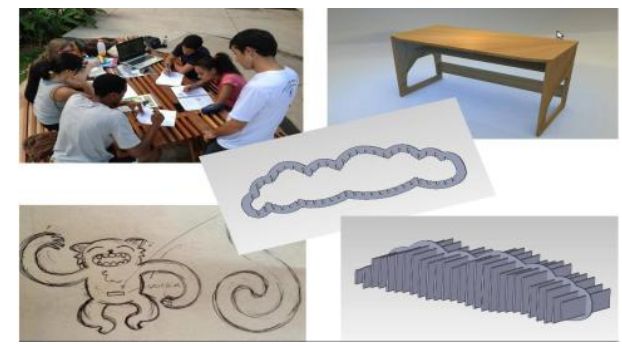

Figura 1 - Processo criativo

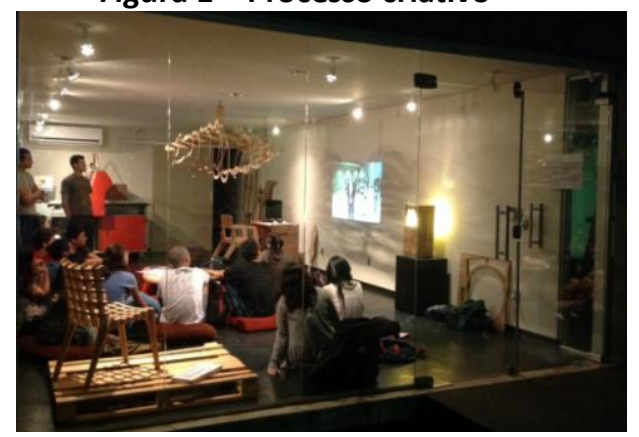

Figura 3 - espaço do Sagui Lab

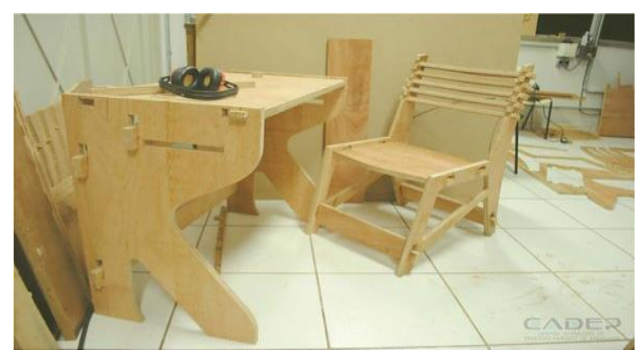

Figura 2 - móveis do CADEP

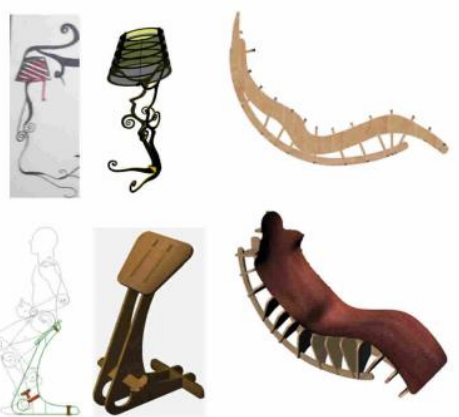

Figura 4 - designs oficinas

Dentro do compromisso com a abertura, além da simples metodologia, se está experimentando com processos colaborativos e inovação social, baseados nas soluções oferecidas pelas mesmas comunidades. Para isso se tomou a aula de linguagens contemporâneas, uma matéria optativa da faculdade de design da Unesp, para pôr em prática o Open Design. Nessa aula, se abriu um site do Sagui Lab (https://sites.google.com/site/saguilabunesp/) para que os estudantes propuseram de forma livre problemas que eles consideram importantes em seu entorno, surgindo propostas interessantes com reformas dos banheiros, adequações físicas de alguns espaços da universidade, projetos tecnológicos, ambientais, e projetos de impacto social como o design de brinquedos para crianças com fabricação digital, próteses, entre outros onde eles oferecem seu tempo livre para projetar algumas soluções de forma colaborativa.

É interessante notar que o Design Aberto não é só um discurso, é uma realidade em processo de maturação, com possibilidades de oferecer soluções aos problemas sociais por meio da transformação do entorno. Além disso, é importante sublinhar que as comunidades mesmas podem oferecer soluções a seus próprios 
problemas utilizando o design com ferramenta de projetual, criando espaços democráticos e participativos. Isso é o open design como ferramenta para a abertura da sociedade.

\section{CONSIDERAÇÕES FINAIS}

Neste trabalho se fez uma dissertação de vários temas: a abertura, as tecnologias da informação e da comunicação, o Open Design e a cultura Open Design no Brasil. A partir desses temas demonstramos a importância do conceito de abertura e suas implicações no design, indicando as novas formas de organização geradas pela cocriação e pela criação de novos ambientes, cenários e atores envolvidos nesse processo, que apontam a transdisciplinaridade promovendo ações mais democráticas para a coletividade, visando a um mundo melhor, mais justo e igualitário.

$\mathrm{Na}$ análise da abertura, do ponto de vista de vários autores e campos do conhecimento, foi encontrado um conceito emancipador, que se manifesta na luta contínua contra a opressão e na liberação do indivíduo do totalitarismo exercido em qualquer âmbito. A abertura é uma luta contínua que possibilita uma sociedade democrática, tolerante e justa. É por isso que a abertura está se tornando uma prática organizacional ou modelo que oferece possibilidades para a sobrevivência e a superação dos problemas atuais de maneira colaborativa e democrática.

O design se converte em uma possibilidade de pensamento que oferece ferramentas para buscar melhores soluções, por isso a importância do conceito de abertura agora unido ao design, ou seja, a fusão de um pensamento projetual, transformador, criador e inovador, com um conceito liberador, emancipador, transparente, justo e integrador. Desse ponto de vista, o Open Design já não é apenas uma prática projetual, o Open Design é a recuperação da capacidade do homem, ou melhor, das comunidades, para adaptar e transformar seu ambiente natural que estava monopolizado por um modo de produção fechado, individualista, egoísta e monopolizador. O Open Design é agora a emancipação para um modo de produção comunitário, libertador, transparente, aberto, baseado no trabalho livre, colaborativo e cooperativo.

\section{REFERÊNCIAS}

ABEL, VANBAS et al. Open design now: Why Design Cannot Remain Exclusive. Amsterdam: BIS publishers, 2011.

AICHER, O. Analógico y digital. Traducción: Yves Zimmermann. Barcelona: Gustavo Gili, 2001.

ANDERSON, C. Makers: the new industrial revolution. 1th. ed. New York: Crown Business, 2012.

BARTHES, R. O rumor da língua. Tradução: Mário Laranjeira. [s.I.] Editora brasiliense, 1998.

BENKLER, Y. The wealth of networks: how social production transforms markets and freedom. New Haven: Yale University Press, 2006.

BERGSON, H. The two sources of morality and religion. Tradução: Ashley Audra;

Cloudesley Brereton. London: MacMillan and co., 1935.

BERTANLANFFY, L. VON. Teoría general de los sistemas: Fundamentos, desarrollo, aplicaciones. Tradução: Juan Almela. $1^{a}$. ed. México D.F: Fondo de Cultura Económica, 1976. 
BESSEN, J. E.; NUVOLARI, A. Knowledge Sharing Among Inventors: Some Historical Perspectives. Boston University. School of Law, Law and Economics Research Paper No. 11-51; LEM Working Paper 2011/21, 2011. Disponível em:

<http://www.bu.edu/law/faculty/scholarship/workingpapers/documents/BessenJNuvolariA101411fin.pdf>. Acesso em: 20 dez. 2013

BONSIEPE, G. Design, cultura e sociedade. Tradução: Anamaría Bacci. São Paulo:

Blucher, 2011.

CHESBROUGH, H. W. The era of Open Innovation. A special collection of innovation and management insights from MIT Sloan Management Review: Top 10 Lessons on the new business of innovation, v. Winter 2011, p. 35-41, 2011.

CROSS, N. Engineering design methods: strategies for product design. Chichester, England; Hoboken, NJ: J. Wiley, 2008.

ECO, U. Obra aberta: forma e indeterminação nas poéticas contemporâneas. $8^{a}$. ed. ed. São Paulo: Perspectiva, 1991.

FREE CULTURAL WORKS. Definition/Pt. Disponível em:

<http://freedomdefined.org/Definition/Pt>. Acesso em: 29 nov. 2013.

GERSHENFELD, N. Fab: The Coming Revolution on Your Desktop--from Personal

Computers to Personal Fabrication. New York: Basic Books, 2005.

GORZ, A. O Imaterial: conhecimento, valor e capital. Tradução: Celso Azzan Junior.

São Paulo: Annablume, 2005.

HESS, C.; OSTROM, E. (EDS.). Understanding Knowledge as a Commons: From Theory

to Practice. Cambridge, MA: The MIT Press, 2007.

HUMMELS, C. Teaching attitudes, skills, approaches, structure and tools. In: Open

Design Now: Why Design Cannot Remain Exclusive. Amsterdam, The Netherlands: BIS publishers, 2011. p. 162-167.

ILLICH, I. Tools for Conviviality. [s.I: s.n.]. Disponível em:

<http://www.mom.arq.ufmg.br/mom/arq_interface/3a_aula/illich_tools_for_convivial ity.pdf>.

MCCRAE, R. R. Social consequences of experiential openness. Psychological bulletin, v. 120, n. 3, p. 323-337, 1996.

MUL, J. DE. Redesigning design. In: Open Design Now: Why Design Cannot Remain

Exclusive. Amsterdam, The Netherlands: BIS publishers, 2011. p. 34-39.

ODF. Preamble to First Draft of the "Open Design Definition”. Disponível em:

<http://www.opendesign.org/odd.html>. Acesso em: 12 fev. 2014.

PAPANEK, V. J. Diseñar para el mundo real: ecología humana y cambio social.

Traducción: Luis Cortés. Madrid: H. Blume, 1977.

PETERS, M. A. On the Philosophy of Open Science. Review of Contemporary

Philosophy, v. 9, p. 105-142, 2010.

POPPER, K. R. A sociedade aberta e seus inimigos. Tradução: Milton Amado. São

Paulo: Belo Horizonte: EDUSP; Itatiaia, 1974. v. 1

ROSSI, D. C.; NEVES, H. Open Design: Uma experiência Aberta e Colaborativa para o ensino de Design. In: CARRARA, C. et al. (Eds.). Ensaios em Design: ensino e produção de conhecimento. $1^{\text {a }}$. ed. Bauru, SP: Canal 6, 2011. p. 60-81.

THACKARA, J. Into the open. In: Open Design Now: Why Design Cannot Remain Exclusive. Amsterdam, The Netherlands: BIS Publishers, 2011. p. 42-47.

Agradecimentos: a CAPES, o CADEP, o pessoal do CADEP, o Sagui Lab e a turma da aula de linguagens contemporâneas. 